\title{
JURISPRUDENCIA CONSTITUCIONAL
}

LUCRECIO REBOLLO DELGADO

Profesor Asociado del Departamento de Derecho Constitucional de la UNED 


\section{SUMARIO}

1. Resumen de actividad del Tribunal Constitucional del tercer cuatrimestre de 1999. 2. Recursos de amparo. 3. Recursos de inconstitucionalidad. 4. Cuestiones de inconstitucionalidad. 5. Conflictos de competencia. 6. Resumen de DOCTRINA. 


\title{
JURISPRUDENCIA CONSTITUCIONAL
}

\author{
POR \\ LUCRECIO REBOLLO DELGADO \\ Profesor Asociado del Departamento \\ de Derecho Constitucional de la UNED \\ 1. RESUMEN DE ACTIVIDAD \\ DEL TRIBUNAL CONSTITUCIONAL \\ DEL TERCER CUATRIMESTRE DE 1999
}

El Tribunal Constitucional ha dictado durante este periodo un total de 93 sentencias y 1 Auto, distribuidos de la forma que refleja el presente cuadro:

\begin{tabular}{lcccc}
\hline & $\begin{array}{c}\text { Recursos } \\
\text { de amparo }\end{array}$ & $\begin{array}{c}\text { Recursos de } \\
\text { Inconstituc. }\end{array}$ & Cuestiones & Conflictos \\
\hline Sentenciàs & 84 & 5 & 1 & 3 \\
\hline Autos & 1 & & & \\
\hline
\end{tabular}

Como es costumbre en esta sección de la revista, agrupamos el número de recursos de amparo atendiendo al derecho que se dilucida o que es parte central del argumento del Tribunal. 


\section{RECURSOS DE AMPARO}

\section{PRINCIPIO DE IGUALDAD}

STC $\quad 155 / 99$ de 14 de septiembre

STC $\quad 156 / 99$ de 14 de septiembre

STC $\quad 158 / 99$ de 14 de septiembre

STC $\quad 172 / 99$ de 27 de septiembre

STC $\quad 182 / 99$ de 11 de octubre

STC $\quad 194 / 99$ de 25 de octubre

STC $\quad 203 / 99$ de 8 de noviembre

STC $\quad 215 / 99$ de 29 de noviembre

STC $216 / 99$ de 29 de noviembre

STC $217 / 99$ de 29 de noviembre

STC $\quad 220 / 99$ de 29 de noviembre

STC 227/99 de 13 de diciembre

STC $240 / 99$ de 20 de diciembre

\section{DERECHO A LA INTIMIDAD}

STC 202/99 de 8 de noviembre

STC 224/99 de 13 de diciembre'

\section{LIBERTAD DE EXPRESIÓN E INFORMACIÓN}

STC $\quad 154 / 99$ de 14 de septiembre ${ }^{2}$

STC $\quad 187 / 99$ de 25 de octubre

STC $\quad 192 / 99$ de 25 de octubre

STC 214/99 de 20 de diciembre

\section{SECRETO DE LAS COMUNICACIONES}

STC $\quad 166 / 99$ de 27 de septiembre

STC $\quad 171 / 99$ de 27 de septiembre

STC $\quad 188 / 99$ de 25 de octubre

STC $236 / 99$ de 20 de diciembre

STC $237 / 99$ de 20 de diciembre

1 Se comenta de forma extensa ésta resolución en el apartado de Resumen de Doctrina.

2 Se comenta de forma extensa ésta resolución en el apartado de Resumen de Doctrina 


\section{DERECHO A LA INVIOLABILIDAD DEL DOMICILIO}

STC $239 / 99$ de 20 de diciembre

\section{LIBERTAD SINDICAL}

STC 201/99 de 8 de noviembre

\section{DERECHO AL HONOR}

STC $\quad 180 / 99$ de 11 de octubre

\section{VULNERACIÓN DE LA CLÁUSULA DE CONCIENCIA}

STC $\quad 199 / 99$ de 8 de noviembre

DERECHO DE ACCESO EN CONDICIONES DE IGUALDAD A CARGO PÚBLICO

STC $\quad 151 / 99$ de 14 de septiembre

STC $\quad 185 / 99$ de 11 de octubre

\section{PRINCIPIO DE LEGALIDAD PENAL}

STC $\quad 177 / 99$ de 11 de octubre

\section{LIBERTAD PERSONAL Y HABEAS CORPUS}

STC $\quad 174 / 99$ de 27 de septiembre

STC 232/99 de 13 de diciembre

\section{TUTELA JUDICIAL EFECTIVA}

1. Deficiencias procesales

STC $\quad 152 / 99$ de 14 de septiembre

STC $\quad 153 / 99$ de 14 de septiembre

STC $\quad 164 / 99$ de 27 de septiembre

STC $\quad 168 / 99$ de 27 de septiembre

STC $\quad 170 / 99$ de 27 de septiembre

STC $173 / 99$ de 27 de septiembre

STC $\quad 178 / 99$ de 11 de octubre 
STC $\quad 179 / 99$ de 11 de octubre

STC $190 / 99$ de 25 de octubre

STC $191 / 99$ de 25 de octubre

STC $\quad 195 / 99$ de 25 de octubre

STC $\quad 197 / 99$ de 25 de octubre

STC 204/99 de 8 de noviembre

STC $\quad 205 / 99$ de 8 de noviembre

STC $214 / 99$ de 29 de noviembre

STC $218 / 99$ de 29 de noviembre

STC $219 / 99$ de 29 de noviembre

STC $222 / 99$ de 29 de noviembre

STC $228 / 99$ de 13 de diciembre

2. Presunción de inocencia

STC $\quad 161 / 99$ de 27 de septiembre

STC 209/99 de 29 de diciembre

STC $229 / 99$ de 13 de diciembre

STC 238/99 de 20 de diciembre

3. Incongruencia en la resolución judicial

STC $\quad 165 / 99$ de 27 de septiembre

STC $\quad 193 / 99$ de 25 de octubre

STC 206/99 de 8 de noviembre

STC $210 / 99$ de 29 de noviembre

STC $\quad 212 / 99$ de 29 de diciembre

\section{Acceso a la jurisdicción}

STC $\quad 157 / 99$ de 14 de septiembre

STC $\quad 167 / 99$ de 27 de septiembre

STC 211/99 de 29 de noviembre

5. Derecho a un proceso sin dilaciones indebidas

STC $\quad 160 / 99$ de 14 de septiembre

STC $\quad 184 / 99$ de 11 de octubre

STC $\quad 198 / 99$ de 25 de septiembre

STC 223/99 de 29 de noviembre

STC $230 / 99$ de 13 de diciembre

STC $231 / 99$ de 13 de diciembre 


\section{Acceso a los recursos}

STC $\quad 163 / 99$ de 27 de septiembre

STC $\quad 189 / 99$ de 25 de octubre

STC $213 / 99$ de 29 de noviembre

STC $221 / 99$ de 29 de noviembre

STC $225 / 99$ de 13 de diciembre

STC $\quad 226 / 99$ de 13 de diciembre

\section{Refomartio in peius}

STC $\quad 196 / 99$ de 25 de octubre

\section{Indefensión}

STC $\quad 150 / 99$ de 14 de septiembre

STC $\quad 169 / 99$ de 27 de septiembre

STC $\quad 181 / 99$ de 11 de octubre

\section{Derecho al juez legal}

STC $\quad 183 / 99$ de 11 de octubre

\section{Derecho a un juez imparcial}

STC $\quad 162 / 99$ de 27 de septiembre ATC 232/99 de 11 de octubre

\section{RECURSOS DE INCONSTITUCIONALIDAD}

STC $176 / 99$ de 30 de septiembre. Resuelve el recurso promovido por el Presidente del Gobierno contra el art. 10.3 de la Ley del Parlamento de Cataluña 12/993, de 4 de noviembre por la que se crea el Instituto para el desarrollo de las Comarcas del Ebro. La sentencia estima el recurso, pero se formulan dos votos particulares, a los que se adhieren otros dos magistrados y en los que se propugna una sentencia interpretativa.

STC 207/99 de 11 de noviembre. Resuelve el recurso promovido por el Presidente del Gobierno contra los artículos 47.3 y 48 de la Ley Foral de Navarra 7/1989 sobre medidas de intervención en el suelo y la vivienda por la que se establece un régimen de infracciones y sanciones de los notarios y registradores de la propiedad. El Tribunal Constitucional estima parcialmente el recurso. Se declara nulo el art. 47.3 por entender que son competencias del Estado. 
STC 208/99 de 11 de noviembre. Se resuelven los recursos acumulados promovidos respectivamente por el Gobierno Vasco y el Consejo Ejecutivo de la Generalidad de Cataluña con respecto a la Ley 16/89 de 17 de julio de Defensa de la Competencia. El Tribunal estima parcialmente el recurso. A la sentencia se le formulan dos votos particulares: uno, realizado por el Magistrado Jiménez de Parga, que manifiesta que el recurso habría de ser desestimado por corresponder al Estado la potestad normativa de ejecución en materia de defensa de la competencia; el segundo, realizado por el Magistrado Garrido Falla, coincide con el fallo, si bien lo hace con otros argumentos.

STC 233/99 de 16 de diciembre. Resuelve la citada sentencia los recursos y cuestiones de inconstitucionalidad acumulados e interpuestos por el Consejo Ejecutivo de la Generalidad de Cataluña, el Parlamento de Cataluña y sesenta diputados, contra la Ley 39/1988 de 28 de diciembre reguladora de las Haciendas Locales. El resumen del contenido de la sentencia es tarea considerablemente difícil, dado el gran número de asuntos que trata y la extensión de los mismos. Aborda de manera concreta los siguientes temas: intimidad frente a la protección de datos de carácter personal, la reserva de ley tributaria, la seguridad jurídica y el principio de igualdad. Declara inconstitucional el art. 45.1 de la citada ley, del resto de artículos establece su constitucionalidad, siempre que sean interpretados conforme establece la sentencia. A la presente resolución se le formulan dos votos particulares.

STC 235/99, de 16 de diciembre. Resuelve el recurso de inconstitucionalidad interpuesto por el Consejo ejecutivo de la Generalidad de Cataluña contra determinados preceptos de la Ley 3/1994 de 14 de abril, por la que se adapta la legislación española, en materia de entidades de crédito, a la Segunda Directiva de Coordinación Bancaria y de normativa relativa al sistema financiero. Se estima parcialmente el recurso y se establece que la remisión que la citada Ley realiza al Título I de la Ley 28/1988, reguladora de la Disciplina e Intervención de las Entidades de Crédito, que realiza el apartado quinto de la Disposición Adicional Primera, vulnera competencias de la Comunidad Autónoma. Se formula voto particular por el Magistrado Jiménez de Parga, concurrente con el fallo, y del Magistrado Vives Antón, parcialmente concurrente con el fallo.

\section{CUESTIONES DE INCONSTITUCIONALIDAD}

STC 243/99 de 16 de diciembre. Se resuelve cuestión promovida por el Tribunal Superior del País Vasco respecto de la Disposición Adi- 
cional vigésima de la Ley 37/1988, de 28 de diciembre (Presupuestos Generales del Estado para 1989) por la que se establece el requisito de edad para el pase a la situación de segunda actividad de los miembros del Cuerpo Nacional de Policía. Se declara la inconstitucionalidad de la disposición objeto de la cuestión de inconstitucionalidad.

\section{CONFLICTOS DE COMPETENCIA}

STC 175/99 de 30 de septiembre. Resuelve conflicto promovido por el Gobierno Vasco contra algunos preceptos de la Orden Ministerial de Interior de 2 de noviembre de 1989, en virtud de la cual se establecen y regulan las modalidades de libros de registro y otros documentos de control de determinados establecimientos. EI Tribunal Constitucional estima parcialmente el recurso. Formula voto particular discrepante el Magistrado Jiménez de Parga, al que se adhieren los Magistrados Mendizábal Allende y Garrido Falla.

STC 186/99 de 14 de octubre. Resuelve el conflicto positivo promovido por la Generalidad de Cataluña en relación a la Orden del Ministerio de Industria, Comercio y Turismo de 3 de junio de 1992, relativa a la concesión de subvenciones del Plan de Promoción de Diseño Industrial. El Tribunal estima parcialmente el recurso, estableciendo que la competencia para la asignación de subvenciones corresponde a la Comunidad Autónoma, a excepción de las que afectan al fomento de la actividad investigadora.

STC 242/99 de 21 de diciembre. Resuelve los conflictos acumulados promovidos por el Consejo Ejecutivo de la Generalidad de Cataluña en relación con algunas ordenes y resoluciones del Ministerio de Industria, Comercio y Turismo que articulan las ayudas del Plan FUTURES (Plan de Competitividad del Turismo Español). La sentencia estima parcialmente el recurso, estableciendo que determinados ámbitos regulados por las citadas normas, son competencia de la Comunidad Autónoma referida.

\section{RESUMEN DE DOCTRINA}

STC 224/99, de 13 de diciembre. Se pronuncia en esta resolución la Sala Segunda, al respecto del acoso sexual, $y$ hay en ella diversos aspectos dignos de comentario. 
Dña. Ana María Izquierdo Esteban interpuso recurso de amparo contra resolución del Tribunal Superior de Justicia de Galicia, que a su vez revoca la sentencia de instancia, en la que se declaraba que la actora había sido agredida sexualmente por el empresario. Recordemos que la actora es empleada única de un vídeo club. La sentencia de primera instancia establecía probada la existencia de un acto manifiesto y claro de contenido sexual o libidinoso, ya sea de forma física o de palabra, directa o a través de insinuaciones que claramente persiguen aquella finalidad. Queda constatado ello en el siguiente texto reproducido y probado:

"El Sr. Beloso (dueño del vídeo club) en una ocasión tocó a la actora en el trasero y ella le amenazó con darle una hostia si volvía a hacerlo, ante lo cual el Sr. Beloso le pidió disculpas. En múltiples ocasiones el demandado Sr. Beloso hizo alusiones sexuales a la actora, que la incomodaban, como que podía acostarse con él, seguir felizmente casada y que ello reforzaría la vida matrimonial, o que se le iban las manos a la blusa que llevaba la actora, o que no tuviera complejos de pechos grandes porque él veía que los tenia muy bonitos. El Sr. Beloso provocaba roces físicos continuos con la actora, sólo por el hecho de cruzarse en la tienda y llegó a ofrecerle las llaves de una casa que tenía y hacerle manifestaciones como "cuando lo hagas conmigo verás la diferencia" ".

El fundamento de la Sala de lo Social del Tribunal Superior de Justicia de Galicia para entender no ajustada a derecho la resolución de instancia, es en esencia, la inexistencia de un elemento que erradica la negativa clara, terminante e inmediata por parte de la mujer afectada, al mantenimiento de dicha situación, a través de actos que pongan de relieve el rechazo total y absoluto a la actitud del empresario. Extrae esta conclusión la Sala, del hecho de que la demandante y el empresario asistieron a una cena, acompañados de sus respectivos cónyuges en casa de éste último, y con posterioridad, la misma demandante de amparo, invitó a tomar café en su casa al empresario. Argumentando a continuación que uaunque no existiese situación de persecución o acoso y sí tan solo alguna insinuación o alusión de contenido sexual, por parte del empresario, que la actora considerase compatible con el trabajo, en modo alguno se compaginaría con esa concurrencia a su domicilio e invitaciones mutuas, que sólo se admiten dentro de un clima de amistad y cordialidad".

El Ministerio Fiscal ante el Tribunal Constitucional solicitó la desestimación del amparo por estimar que la Sentencia impugnada no lesiona derechos fundamentales. 
El Tribunal Constitucional plantea la resolución del recurso rechazando entrar en aspectos probatorios, que los acepta, y fundamenta su deliberación en la existencia o no, de lesión de tres derechos fundamentales: la intimidad personal (art. 18.1 CE), el atentado a una esfera tan personalísima como es la sexualidad en un ámbito laboral que actúa en desdoro de la dignidad humana (art. 10.1 CE); y por último la conexión de estos derechos con los de la mujer a no ser discriminada por razón de sexo, cuando tales comportamientos agresivos, contrarios a los valores constitucionales, puedan afectar todavía en el día de hoy, más a las mujeres que a los hombres (art. $14 \mathrm{CE}$ ).

Para esclarecer si ha existido intromisión ilegítima en el derecho a la intimidad, el TC pone en relación los contenidos del art. 18.1 CE, 184 del Código Penal y 4.2 e) del Estatuto de los Trabajadores. También acude a las Resoluciones del Consejo de Comunidades Europeas de 29 de mayo de 1990 y 27 de noviembre de 1991 para establecer de forma concreta el contenido del denominado "acoso sexual». En virtud de la normativa citada, se considera como tal la existencia de requerimientos no queridos ni pedidos de empleadores o compañeros, que ponen en peligro la estabilidad en el empleo, la promoción, la formación profesional, o cualesquiera otras condiciones en el trabajo o en el salario. También debe incluirse en el concepto de acoso sexual, los comportamientos de carácter libidinoso no deseados por generar un ambiente laboral desagradable, incómodo, intimidatorio, hostil, ofensivo o humillante para el trabajador. Añade a estos contenidos el TC, la necesidad de que estos comportamientos sean los suficientemente graves "como para crear tal entorno negativo y lo sea, por otra parte, no sólo según la percepción subjetiva o la sensibilidad particular de quien lo padece, sino objetivamente considerada. Por tanto, en esta modalidad del acoso hay algo más que una repercusión negativa sobre una concreta condición de trabajo del acosado, o una explícita discriminación en las condiciones de trabajo.

En resumen, para que exista un acoso sexual ambiental constitucionalmente recusable, ha de exteriorizarse requiere: "una conducta por medio de un comportamiento físico o verbal, manifestado, en actos, gestos, palabras, comportamiento, y que además, se perciba como indeseado e indeseable por su víctima o destinataria, y que, finalmente, sea grave, capaz de crear un clima radicalmente odioso e ingrato, gravedad que se erige en elemento importante del concepto".

De esta forma, el elemento dirimente de la existencia de acoso sexual o no, lo constituye la constatación de una negativa clara, terminante e inmediata, por parte de la mujer afectada al mantenimiento de 
dicha situación, y que ésta se manifieste a través de actos que pongan de relieve el rechazo total y absoluto a la actitud del que acosa. Estas circunstancias a juicio de la Sala de los Social del Tribunal Superior de Justicia de Galicia no se dieron, en virtud de lo cual, desestimó las pretensiones de la ahora demandante en amparo.

Por el contrario, para el Tribunal Constitucional sí existe una manifestación clara y objetiva de desagrado e incomodación de la actitud del empresario. Así lo corrobora cuando manifiesta que "pueden espigarse datos, en el relato de lo sucedido que revelan la reacción airada de la víctima frente a los primeros avances, así como su incomodidad $y$ desagrado ante los requerimientos del empresario, con indicios racionales de que tal conducta no era deseada ni deseable".

Si bien es intachable la argumentación jurídica realizada por el Tribunal, y que sirve de fundamento suficiente para otorgar el amparo, a mi juicio, se debilita enormemente en la apreciación, justamente, de una actitud de negativa terminante por parte de la empleada, o en todo caso, puede decirse que ésta es titubeante. A juicio del Tribunal es suficiente con que le comunicara los hechos a sus antiguas compañeras de trabajo, o que acudiera al servicio de información y asesoramiento de los derechos de la mujer del Concello de Vigo para recabar asesoramiento. Pero por el contrario, no estima como elementos que pueden deshacer la manifiesta pretensión de rechazo, el que la recurrente en amparo accediera a cenar con el empresario o admitiera las invitaciones de éste a tomar café, ya que todas estas situaciones facilitarían en todo caso, la actitud libidinosa del empresario o en suma, alimentarían sus pretensiones sexuales frente a la empleada, y ella no consigue con ello erradicarlas.

STC 154/99, de 14 de septiembre. Se resuelve en esta sentencia por parte de la Sala Primera del TC, el recurso de amparo interpuesto por Prensa Española S. A. ${ }^{3}$ y Dña. Sara Caldero Prieto ${ }^{4}$.

Los hechos relevantes para el conocimiento del asunto son sucintamente los siguientes:

Con motivo del fallecimiento, el 16 de septiembre de 1986, en el Centro de Educación Especial de San Francisco, de Vigo, de una menor de doce años de edad y disminuida psíquica, el Juzgado de Instrucción n. 9 de Vigo incoó diligencias penales. La autopsia practicada al cadá-

3 Editora del diario $A B C$.

4 Corresponsal del diario $A B C$ en Vigo, en 1986. 
ver de la expresada menor puso de relieve, según un informe médicoforense, la existencia de una dilatación anal y vaginal amplia, frecuente y continua. La práctica de otros reconocimiento médico-forense a otras niñas, también disminuidas psíquicas y compañeras de colegio de la menor fallecida, puso de manifiesto la existencia, en tales niñas, de anomalías similares a la detectada en la autopsia de aquélla. Todo ello condujo al procesamiento de $D$. Onésimo Juncos Rabadán, profesor logopeda de dichas menores, en concepto de presunto autor de los delitos de violación y abusos deshonestos. El diario $A B C$ publica los días 17, 18 y 19 de octubre de 1986 varias informaciones, de las que era autora Dña. Sara Caldero con los siguientes titulares "pueden ser cuarenta las niñas deficientes mentales violadas por un profesor en Vigo", "se eleva a diez el número de niñas asaltadas sexualmente en Vigo", «el presunto violador podría ser absuelto por falta de pruebas». En el contenido de las informaciones se ponía de manifiesto a su vez, datos relativos al estado civil y forma de convivencia del acusado.

En noviembre de 1986, el Juzgado de Instrucción, mediante auto, dejó sin efecto el procesamiento del Sr. Juncos Rabadán. La Audiencia Provincial de Pontevedra, por Auto de mayo de 1987, denegó el procesamiento de D. Onésimo Juncos Rabadán solicitado por las acusaciones particulares.

El antes acusado, promueve en virtud de la Ley Orgánica 1/82 y Ley 62/78, demanda contra Dña. Sara Calderón y contra el diario ABC, al entender que las informaciones publicadas, eran atentatorias contra su honor, su intimidad y su propia imagen. Solicita además una indemnización de cincuenta millones de pesetas.

En primera resolución, el juzgado de lo civil de Vigo desestima la demanda en todos sus pedimentos. Recurrida la sentencia, la Audiencia Provincial revocó y estimó parcialmente la demanda, declarando que había existido una intromisión ilegítima en el honor y la intimidad del demandante, condenando a los demandados al pago de la cantidad de diez millones de pesetas. La Audiencia aprecia que las publicaciones objeto de la causa suponen un atentado contra el honor del demandante al contener expresiones "que, lejos de transcribir, sin más, información objetiva, escarnecen y humillan ese derecho fundamental, atribuyendo al demandante directamente la comisión de delitos que jamás fueron acreditados; imputaciones en las que es evidente el carácter difamatorion. También establece que en las publicaciones existen unos juicios de valor "encaminados a hacer aparecer a una persona ante la opinión pública como autora de una serie de delitos, recurriendo para ello a un tratamiento peyorativo y falto de objetividad de la noticia". En 
última instancia, la Audiencia aprecia también una vulneración de la intimidad del demandante, dado que se revelan datos sobre su vida privada que en absoluto tienen relación con los hechos investigados. Recurrida esta resolución ante el Tribunal Supremo, fue desestimada, propiciando el recurso de amparo del que ahora conoce el Tribunal Constitucional y que es objeto de nuestro estudio.

A juicio de los demandantes de amparo, procede éste debido a que se ha vulnerado su derecho a comunicar información veraz, toda vez que los reportajes en cuestión estaban amparados por ese derecho fundamental, al tratarse de informaciones contrastadas y dirigidas a un fin legítimo, con el que se hallan directamente relacionadas y respetuosas con el honor y dignidad del afectado.

El Tribunal Constitucional centra el objeto de recurso en la apreciación de existencia o no de vulneración del derecho a la información reconocido en el art. 20.1 d) CE y el contenido del art. 18.1 CE, es decir, la violación del derecho al honor, aunque como el mismo tribunal indica, aparece también concernido el derecho a la intimidad personal y familiar del Sr. Juncos Rabadán.

Para delimitar el contexto de los derechos en juego, acude el TC a su propia jurisprudencia, de esta forma, el fundamento jurídico segundo de la sentencia que comentamos, recuerda, que los dos inexcusables requisitos para que el ejercicio del derecho a la libre información goce de protección constitucional, son que la información sea veraz y relativa a asuntos de interés general o de relevancia pública, y recuerda también que "en ausencia de alguno de ellos la libertad de información no está constitucionalmente respaldada $y$, por ende, su ejercicio podrá afectar, lesionándolo, a alguno de los derechos que como límite enuncia el art. 20.4 CE. Añade por último en este fundamento jurídico el TC que ula protección constitucional de la libertad de información alcanza un nivel máximo cuando la libertad es ejercitada por los profesionales de la información a través del vehículo institucionalizado de formación de la opinión pública que es la prensa, entendida en su más amplia concepción, circunstancia que sin duda concurre en el presente cason. Y estos son los elementos objetivos por los que el Tribunal se guía en la presente resolución.

Para el TC, las tres primeras informaciones, de los días 17,18 y 19 de octubre de 1986, se producen de forma coetánea con la detención y prisión preventiva del inculpado $D$. Onésimo Juntos, en relación con las supuestas violaciones de varias alumnas, menores de dad y deficientes mentales. En todas ellas se afirma que las niñas "fueron violadas y sodomizadas presuntamente por su profesor de logopedia". 
También en ellas se da a conocer la identidad y profesión del inculpado, así como diversos aspectos de su vida familiar.

De todo ello deduce el TC que la noticia es de relevancia pública, y que la información periodísitica del caso se produjo en relación con hechos noticiables, a pesar de que el inculpado, Sr. Rabadán no lo sea.

Pasa a continuación el Tribunal al análisis de lo negado en las diversas instancias judiciales, es decir, la veracidad de la información, y para ello, al igual que con anterioridad, realiza un resumen de su jurisprudencia. Así, trae a colación las SSTC 143/91, 41/94, 320/94 y $3 / 97$, de las que extrae que "el requisito constitucional de la veracidad de la información ex art. 20.1 d) no se halla ordenado a procurar la concordancia entre la información difundida y la verdad material u objetiva de los hechos narrados, de manera tal que proscriba los errores o inexactitudes en que pueda incurrir el autor de aquélla, sino que, más propiamente, se encamina a exigir del informador un específico deber de diligencia en la búsqueda de la verdad de la noticia y en la comprobación de la información difundida, de tal manera que lo que transmita como hechos o noticias haya sido objeto de previo contraste con datos objetivos o con fuentes informativas de solvencian. Añade por último que el nivel de diligencia exigible al informador adquiere especial intensidad "cuando la noticia divulgada puede suponer, por su propio contenido, un descrédito de la persona a la que la información se refiere".

Las sentencias de instancia habian venido estableciendo de forma sucesiva que las informaciones "no se limitan a narrar hechos de veracidad comprobada, sino a formular numerosos juicios de valor que, no ya subliminalmente, sino de forma abierta y frontal, presentan ante la opinión pública a la persona objeto de dichas informaciones como autor real y verdadero de las supuestas violaciones que estaban siendo objeto de investigación policial y judicial».

Por el contrario, el TC corrobora una inexacta apreciación de los hechos referidos en el caso, de tal forma que reprocha a las diversas instancias, que realicen una ponderación consistente únicamente en equiparar la veracidad informativa con la verdad procesal, es decir la alcanzada conclusivamente en el proceso, situando ambas en el mismo plano o nivel. Por ello concluye el TC que en la ponderación de los dos derechos en tensión, "no es constitucionalmente aceptable estimar que los informadores han incumplido el deber de diligencia en el desempeño de su labor, con el apoyo exclusivo en el solo dato de que el resultado final de las investigaciones llevadas a cabo en el proceso penal haya sido distinto al expuesto o trasmitido por los autores de la 
noticia, sobre la base de los elementos que en tal momento ponía de relieve el proceso penal. Ello, junto a la constatación de que en las referidas informaciones hay alusiones a la buena consideración social y acreditada reputación profesional del Sr. Juncos Rabadán, es suficiente, a juicio del Tribunal Constitucional, para estimar la pretensión de amparo. Por ello en el fallo se reconoce el derecho a Prensa Española S.A. y a Dña. Sara Caldero Prieto a comunicar información veraz, y se anulan las sentencias dictadas tanto por el Tribunal Supremo, como por la Audiencia Provincial. 